\title{
Neutrophil mucosal involvement is accompanied by enhanced local production of interleukin-8 in ulcerative colitis
}

\author{
Y Raab, B Gerdin, S Ahlstedt, R Hällgren
}

\begin{abstract}
The concentration of myeloperoxidase, a neutrophil granule constituent, was measured in the perfusion fluid from sigmoid and rectal segments in patients with ulcerative colitis. The concentrations of myeloperoxidase were increased severalfold in the patients with ulcerative colitis compared with healthy controls pointing to an enhanced neutrophil activity. The release of myeloperoxidase correlated to an enhanced local release of the neutrophil activating peptide interleukin-8 (IL-8). Increased values of tumour necrosis factor (TNF- $\alpha$ ) were also found during intestinal perfusion of the patients and correlated with those of IL-8. The results obtained are compatible with the hypothesis that local mucosal recruitment/activation of neutrophils in ulcerative colitis is mediated by an enhanced IL-8 synthesis. TNF- $\alpha$ may be one relevant factor as a stimulus to IL-8 synthesis. (Gut 1993; 34: 1203-1206)
\end{abstract}

Neutrophil accumulation in the inflamed intestinal mucosa is a prominent feature in ulcerative colitis. The granules of neutrophil granulocytes contain a number of enzymes, for example, myeloperoxidase, which are important in the combat against bacteria.' These granule enzymes, some of which are proteolytic, can be released upon stimulation, together with cytotoxic oxygen metabolites. ${ }^{2}$ Therefore, activated neutrophils may contribute to tissue damage at sites of inflammation. The factor(s) responsible for the mucosal recruitment of neutrophils in ulcerative colitis are not certain. Human neutrophil activating peptide/interleukin-8 (NAP-1/ IL-8) is a single, non-glycosylated peptide chain; its main activities include activation and chemotactic attraction of neutrophils. ${ }^{3-7}$ It was originally isolated from endotoxin treated monocytes but can also be produced by a variety of other cells upon stimulation with a number of cytokines including IL-1 and tumour necrosis factor Departments of Surgery Y Raab B Gerdin

and Internal Medicine, University Hospital R Hällgren

and Pharmacia Diagnostics, Uppsala, Sweden

S Ahlstedt

Correspondence to: Dr R Hällgren, Department of Internal Medicine, University Hospital, Uppsala, Sweden.

Accepted for publication 8 January 1993
(TNF- $\alpha){ }^{8-10}$ This study was performed in an attempt to estimate the mucosal activity of neutrophils in ulcerative colitis and elucidate the possible neutrophil activating role certain cytokines may exert. For this purpose we have measured myeloperoxidase, IL-8, and some cytokines known to induce IL-8 synthesis. The measurements were performed in the perfusion fluid obtained during regional perfusion of inflamed sigmoid and rectal segments.

Patients and methods

We studied 16 patients with proved ulcerative colitis; eight had a disease extension to or beyond the sigmoid colon and eight had an isolated proctitis (eight women and eight men, with a mean age of 35 years, range 20 to 75 ). The diagnosis was based on established criteria including a typical endoscopic appearance supported by histological findings. " All patients had endoscopically active disease of various degrees. The clinical symptoms varied from mild disease with little blood in stools to more active disease with frequent diarrhoea with blood and mucus in all stools. The four degree score of Binder ${ }^{12}$ was used to classify clinical and endoscopic findings. Histological scoring of biopsy specimens was performed on formaldehyde fixed sections. Six patients were not receiving any treatment. Six patients were receiving treatment with oral or enema steroids, or both and two had recently finished treatment with steroids. One patient was treated with sulphasalazine and one with lidocaine enema. The patients were compared with 18 healthy volunteers ( 11 women and seven men, with a mean age of 33 years, range 21 to 64 ). The study was approved by the ethics committee of the medical faculty of Uppsala University.

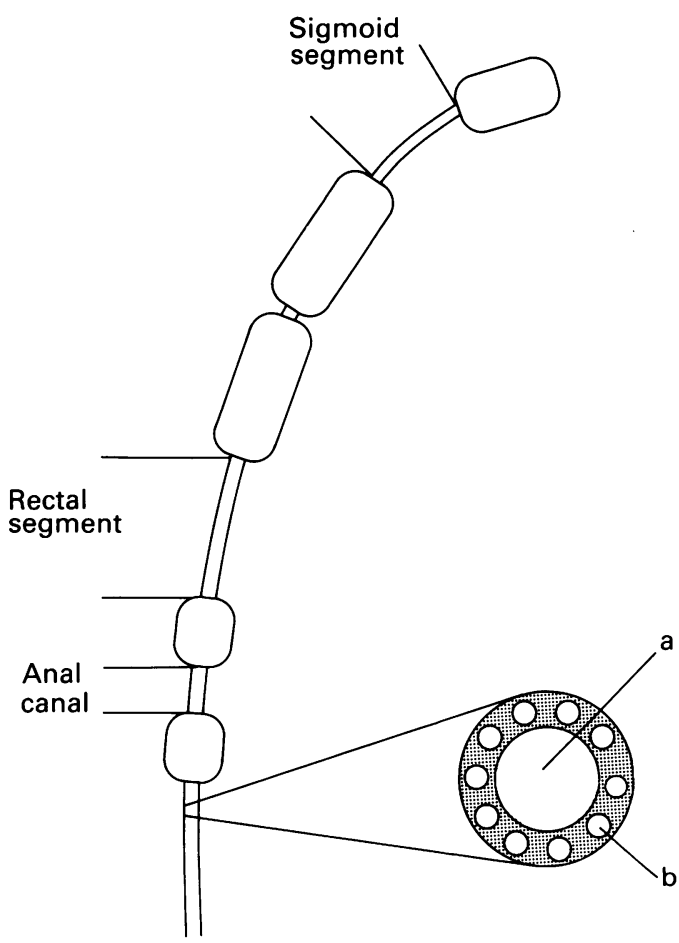

Figure 1: A schematic presentation of the colorectal perfusion system. The perfusion tube with five balloons delimiting one rectal and one sigmoid segment. Two balloons control the position of the tube by surrounding the anal canal. The central channel of the tube (a) was used for the introduction of the tube with an endoscope and decompression of gas and fluids during perfusions; the smaller channels $(b)$ were used to inflate air into the balloons and deliver perfusion fluid to and from the segments and marker dye (for detection of leakage) above the tube. 
The concentrations of interleukin-8 (IL-8), myeloperoxidase (MPO), and tumour necrosis factor $(T N F-\alpha)$ in perfusion fluid from sigmoid/rectal segments in patients with ulcerative colitis and proctitis and controls. The appearance rates of these substances are also given

\begin{tabular}{|c|c|c|c|c|}
\hline & & $\begin{array}{l}\text { IL-8 concentration } \\
\text { appearance rate }\end{array}$ & $\begin{array}{l}\text { MPO concentration } \\
\text { appearance rate }\end{array}$ & $\begin{array}{l}T N F-\alpha \\
\text { concentration } \\
\text { appearance rate }\end{array}$ \\
\hline & Segment & $\begin{array}{l}\mathrm{pg} / \mathrm{ml} \\
\mathrm{ng} / \mathrm{cm} / \mathrm{h}\end{array}$ & $\begin{array}{l}\mu g / l \\
\mu g / c m / h\end{array}$ & $\begin{array}{l}\mathrm{pg} / \mathrm{ml} \\
\mathrm{ng} / \mathrm{cm} / \mathrm{h}\end{array}$ \\
\hline $\begin{array}{r}\text { Proctitis } \\
(n=8)\end{array}$ & $\begin{array}{l}\text { Sigmoid } \\
\text { Rectum }\end{array}$ & $\begin{array}{c}74(48-117)^{\star \star} \\
1 \cdot 6(1 \cdot 0-2 \cdot 5) \\
257(110-589)^{\star \star \star} \\
5 \cdot 1(2 \cdot 5-10 \cdot 2)\end{array}$ & $\begin{array}{c}28(12-66)^{\star \star} \\
0 \cdot 6(0 \cdot 2-1 \cdot 5) \\
132(30-575)^{\star \star \star} \\
2 \cdot 2(0 \cdot 4-13 \cdot 8)\end{array}$ & $\begin{array}{c}9 \cdot 8(7 \cdot 1-14)^{\mathrm{NS}} \\
0 \cdot 21(0 \cdot 16-0 \cdot 28) \\
36(13-98)^{\star \star \star} \\
0 \cdot 7(0 \cdot 3-1 \cdot 7)\end{array}$ \\
\hline $\begin{array}{l}\text { Colitis } \\
\quad(n=8)\end{array}$ & $\begin{array}{l}\text { Sigmoid } \\
\text { Rectum }\end{array}$ & $\begin{array}{c}195(79-468)^{\star \star \star} \\
4 \cdot 2(1 \cdot 7-10 \cdot 5) \\
166(87-316)^{\star \star \star} \\
4 \cdot 3(2 \cdot 2-8 \cdot 3)\end{array}$ & $\begin{array}{r}195(55-708)^{\star \star \star} \\
3 \cdot 1(0 \cdot 8-12 \cdot 6) \\
234(68-832)^{\star \star \star} \\
4.9(1 \cdot 2-20 \cdot 4)\end{array}$ & $\begin{array}{r}25(11-58)^{\star \star} \\
0.5(0 \cdot 2-1 \cdot 3) \\
34(16-72)^{\star \star \star} \\
0.9(0 \cdot 4-1 \cdot 9)\end{array}$ \\
\hline $\begin{array}{l}\text { Controls } \\
(n=18)\end{array}$ & $\begin{array}{l}\text { Sigmoid } \\
\text { Rectum }\end{array}$ & $\begin{array}{c}35(26-47) \\
0 \cdot 7(0 \cdot 5-1 \cdot 1) \\
43(30-62) \\
1 \cdot 0(0 \cdot 6-1 \cdot 5)\end{array}$ & $\begin{array}{l}11(10-13) \\
0 \cdot 20(0 \cdot 17-0 \cdot 23) \\
16(11-23) \\
0 \cdot 3(0 \cdot 2-0 \cdot 5)\end{array}$ & $\begin{array}{l}8 \cdot 1(6 \cdot 0-10 \cdot 7) \\
0 \cdot 17(0 \cdot 13-0 \cdot 25) \\
7 \cdot 2(6 \cdot 8-7 \cdot 8) \\
0 \cdot 16(0 \cdot 14-0 \cdot 19)\end{array}$ \\
\hline
\end{tabular}

Values are given as means and $95 \%$ confidence intervals (differences between patients and controls

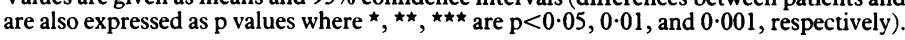

We used a perfusion system where segments of the sigmoid colon and rectum were isolated. Before colorectal perfusion studies, the patients and controls had a bowel preparation as for flexible rectosigmoidoscopy, that is - diet restriction and oral purgative the day before and a nonirritative enema two hours before perfusion. The perfusion instrument was a plastic tube $(16 \mathrm{~mm}$ in external diameter), which was $60 \mathrm{~cm}$ long and contained smaller channels in the tube wall and one large central channel; five latex balloons were attached to the tube (Fig 1). The investigation started with an endoscopic examination up to the junction of the sigmoid descending colon. Before insertion of the tube, it was threaded onto the endoscope. The tube was then introduced up to the sigmoid colon with the endoscope acting as a guide. When the balloons were inflated with air, two $8 \mathrm{~cm}$ long segments were established (Fig 1); one in the rectum (rectal segment) and another in the sigmoid colon (sigmoid segment). After withdrawal of the endoscope, the position of the tube was checked fluoroscopically. To stabilise the position of the

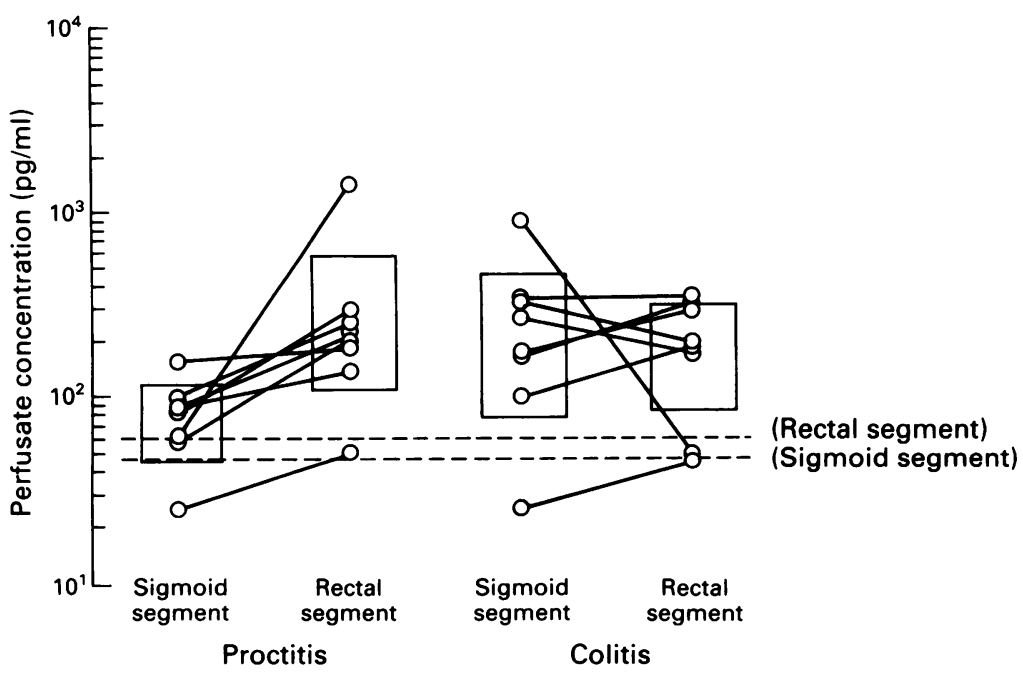

Figure 2: The individual interleukin-8 $(I L-8)$ concentrations in the perfusion fluid from rectal and sigmoid segments in patients with ulcerative colitis. Boxes indicate the confidence intervals of the means in patients grouped with respect to disease extension. The broken lines represent the upper limits for the confidence intervals for $I L-8$ during perfusion of rectal and sigmoid segments in healthy controls. tube, two balloons surrounding the anal canal were inflated (Fig 1).

Using the inflow channels, the rectal and sigmoid segments were continuously perfused at a rate of $3 \mathrm{ml} / \mathrm{min}$ with a perfusion solution containing $120 \mathrm{mM} \mathrm{NaCl}, 5.4 \mathrm{mM} \mathrm{KCl}, 2 \mathrm{mM}$ Na2HPO4, $10 \mathrm{mM}$ glucose, $35 \mathrm{mM}$ mannitol, and $1 \mathrm{~g} / \mathrm{l}$ polyethylene glycol $(\mathrm{Mw} 4000)$. The $\mathrm{pH}$ of the solution was $7 \cdot 2$ and the osmolarity 290 $\mathrm{mmol} / \mathrm{l}$. Aprotinin (10000 IU/ml; Bayer, Leverkusen, Germany) was added to the perfusion solution (10 ml aprotinin/l) to inhibit possible proteolytic activity in the effluent.

The perfusate fluid was collected by the outflow channels from the isolated segments. After 50 minutes of continuous perfusion to obtain steady state conditions, samples of the effluent were collected on ice. The total recovery of perfusion fluid was almost equal to that infused. After centrifugation of the samples, the supernatants were immediately frozen at $-70^{\circ} \mathrm{C}$ until they were analysed. As the assays might even be affected by the presence of small amounts of proteases, phenylmethylsulfonyl fluoride to a final concentration of $2 \mathrm{mM}$ (Sigma Chemical, St Louis) was added to all samples before they were thawed on ice and analysed. Further details of the perfusion system is presented elsewhere. ${ }^{13}$

The granulocyte granule component myeloperoxidase was measured by a radioimmunoassay from Pharmacia Diagnostics, Uppsala, Sweden. IL-8 was determined by a solid phase double ligand ELISA. ${ }^{1+}$ TNF- $\alpha$ was measured by an enzymatic immunoassay obtained from Medgenix, Brussels, Belgium. Interleukin-2 (IL-2) was determined by a radioimmunoassay (Medgenix). Granulocyte macrophage colony stimulating factor (GM-CSF) and interleukin-1 (IL-1 $\beta$ ) were measured by immunometric assays (Medgenix). The perfusion fluid samples were analysed in duplicate and in sequence to avoid inter day variation. The variability was less than $10 \%$ for all methods. The specificity of the assays applied to perfusion fluid was assured by dilution and by recovery experiments showing correlation to the standard curves.

\section{STATISTICS}

To obtain normally distributed values, all values were logarithmically transformed before calculations and statistical analyses. Means and 95\% confidence intervals are presented in text and figures. Differences between groups were calculated with the two tailed Student's $t$ test; $p<0.05$ was considèred significant. Clinical findings related to perfusion data were tested by one way analysis of variance.

\section{Results}

The patients were grouped into those who had a disease extension to or beyond the sigmoid colon (colitis) and those who suffered from an isolated proctitis. In patients with colitis the concentrations of myeloperoxidase were increased by an average of 14 and 18 times in the perfusion fluids from the sigmoid and rectal segments compared with controls $(p<0.001)$. In patients with isolated proctitis, there was an eightfold increase 


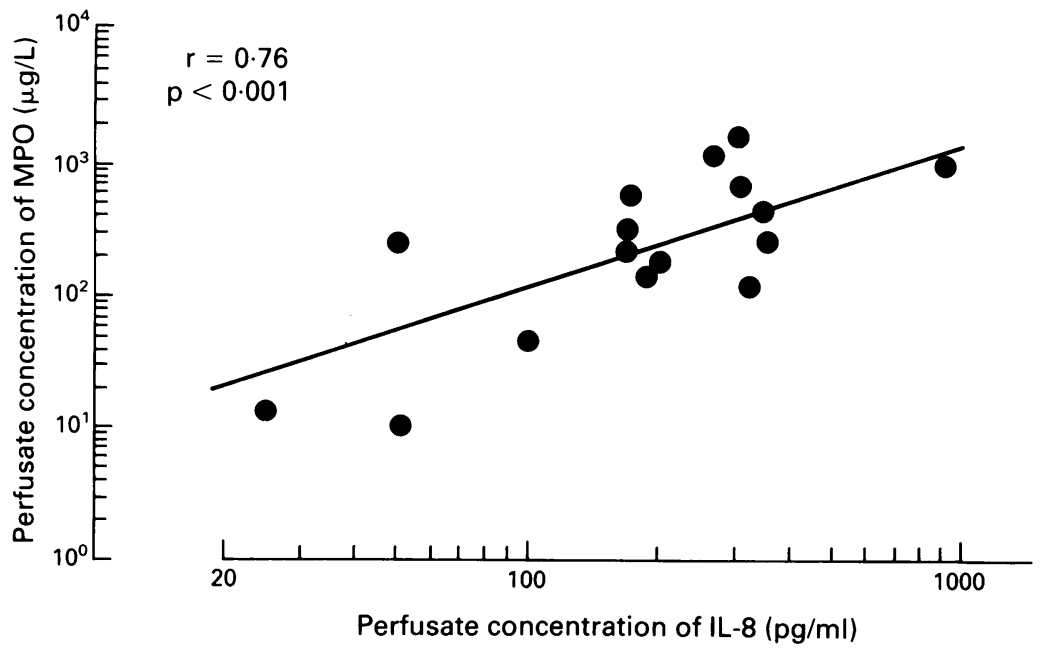

Figure 3: The interleukin-8 $(I L-8)$ concentrations $\mathrm{v}$ the myeloperoxidase $(M P O)$ concentrations in the perfusion fluids from the rectal and sigmoid segments in patients with colitis.

of the mean myeloperoxidase concentration in the rectal segment $(<0 \cdot 001)$ and a twofold increase in the sigmoid segment (Table). The perfusion fluid concentrations of IL-8 were also significantly increased in both segments in colitis and proctitis (Fig 2 and Table). The myeloperoxidase and IL-8 concentrations in sigmoid/ rectal segments were correlated in patients with colitis $(r=0.76, p<0.001 ;$ Fig 3$)$ and in proctitis $(r=0.46, p<0.05)$. Significantly increased values of TNF- $\alpha$ were found in perfusates from both segments in colitis but only from the rectal segment in proctitis (Table). The recovered sigmoid-rectal amounts of TNF- $\alpha$ correlated with the recovered amounts of IL-8 in patients with colitis $(r=0.75, p<0.001 ;$ Fig 3$)$ and proctitis $(r=0.62, p<0.001)$. To compensate for differences in flow rates during perfusion, the appearance rates of myeloperoxidase and cytokines were calculated. The differences between the perfusion fluid concentrations of the components in the patients and those in the controls were similar to the differences in the appearance rates (Table). The values of IL-2, GM-CSF, and IL- $1 \beta$ were below the detection limits.

Most of the patients had clinically mild

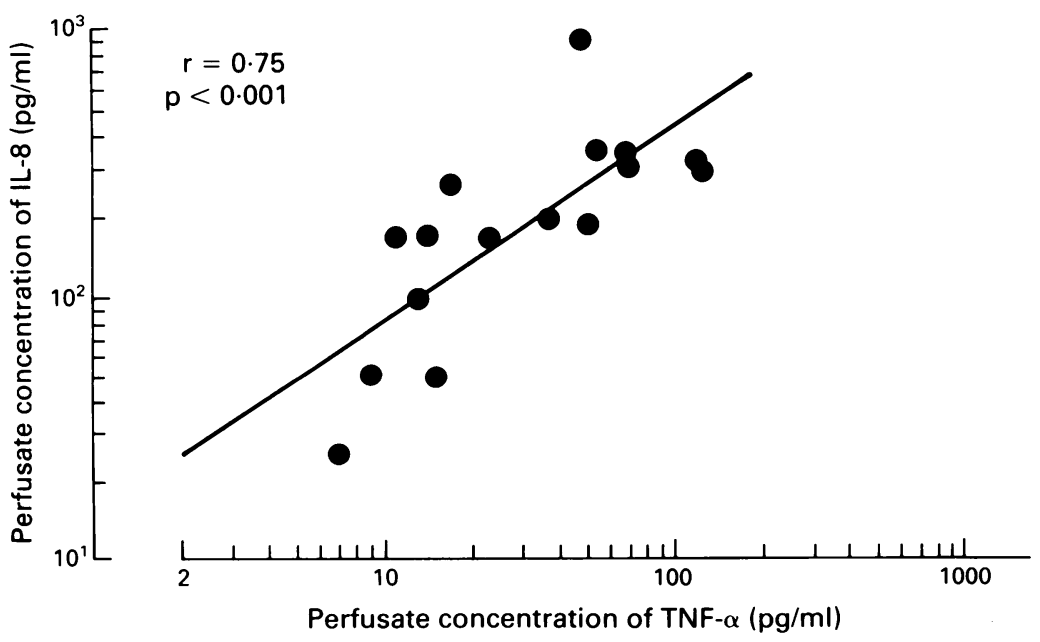

Figure 4: The correlation between the measured amounts of tumour necrosis factor (TNF- $\alpha$ ) and interleukin-8 $(I L-8)$ in the perfusion fluids from rectal and sigmoid segments in patients with colitis. disease. On a four degree scale, the median clinical score was 2 (range 1-3) and the median endoscopic and histologic scores of the affected sigmoid and rectal segments were 2 (range 2-3) and 3 (range $2-3$ ), respectively. We found no significant relation between these scores and the measured substances in perfusion fluid.

\section{Discussion}

During regional perfusion of defined sigmoid and rectal segments from healthy controls and patients with ulcerative colitis we were able to detect measurable amounts of myeloperoxidase. The severalfold increase of the local release of myeloperoxidase in patients should reflect the increased neutrophil accumulation/activity in the inflamed colonic-rectal mucosa. Previous investigators have also shown, by tissue extraction, an increased release of neutrophil granule constituents in the inflamed mucosa in ulcerative colitis. ${ }^{15}$ The potential hazard of persistent local neutrophil activation relates to the ability of the neutrophil to generate toxic oxygen radicals and release myeloperoxidase and other preformed azurophilic enzymes including collagenase, elastase, and cathepsin $G$ with the capacity to destroy the connective tissue matrix. ${ }^{2}$ The very toxic hypohalide anion catalysed by the enzyme myeloperoxidase may also cause tissue damage. ${ }^{1}$

The mechanism recruiting and activating the neutrophils in the intestinal mucosa in ulcerative colitis is probably multifactorial. The finding that increased intestinal release of $\mathrm{IL}-8$ was accompanied by increased release of myeloperoxidase, however, makes IL-8 a possible factor for local activation of polymorphonuclear granulocytes in this disease. IL-8 presumably plays an important part in neutrophil diapedesis through vascular endothelium and focal recruitment at inflamed sites. ${ }^{3-7}$ Thus, intradermal injection in animals results in plasma exudation and massive neutrophil infiltration. ${ }^{16}$ Besides being chemotactic for neutrophils, IL-8 also activates these cells to degranulate and show respiratory burst. The cellular source of enhanced IL-8 synthesis in the inflamed mucosa has not been identified in this study but bacterial lipopolysaccharides, immune complexes, and several cytokines including IL-2, IL-3, TNF- $\alpha$, GM-CSF, and IL-1 are strong inducers to IL-8 production in mononuclear phagocytes. ${ }^{71}$ Endothelial cells and fibroblasts also produce IL-8 in response to IL-1 and TNF- $\alpha .^{8918}$ The finding that TNF- $\alpha$, by contrast with IL-1 $\beta$, IL-2, and GM-CSF, was seen in increased concentrations in colonic-rectal perfusion fluid from patients with ulcerative colitis and also correlated with the increased IL-8 release supports the idea that TNF- $\alpha$ is one possible mediator of enhanced IL-8 synthesis in the inflamed mucosa.

The lack of correlation between differences in myeloperoxidase and cytokine values and disease activity should be interpreted with caution because of the narrow ranges of endoscopic and histological scores in our patients and the treatment they were receiving; steroids definitely affect the inflammatory response and probably also IL- 8 generation. The finding that some of the patients with isolated proctitis also had 
increased release of myeloperoxidase and IL-8 in the seemingly unaffected sigmoid segment might reflect a low degree sigmoid inflammation not detectable by endoscopy.

This study was supported by the Swedish Medical Research Council and the Nanna Svartz Foundation. The authors gratefully acknowledge the technical assistance of Helen Pettersson, Ingela Westin, and Margit Tjernberg, University Hospital, Uppsala The IL-8 analysis performed by Ilona Jones and Lena Elfsman at Pharmacia Diagnostics, Uppsala is appreciated.

1 Klebanoff SJ. Antimicrobial mechanisms in neutrophilic polymorphonuclear leukocytes. Semin Hematol 1975; 12 $117-42$.

2 Weissmann G, Smolen JE, Korchak HM. Release of inflammatory mediators from stimulated neutrophils. $N$ Engl f Med 1980; 303: 27-34.

3 Peveri P, Walz A, Dewald B, Baggiolini M. A novel neutrophil-activating factor produced by human mononuclear phagocytes. 7 Exp Med 1988; 167: 1547-59.

4 Thelen M, Peveri P, Kernen P, von Tscharner V, Walz A, Baggiolini $M$. Mechanism of neutrophil activation by NAF, Baggiolini $M$. Mechanism of neutrophil activation by NAF,
a novel monocyte-derived peptide agonist. FASE B $\mathcal{F} 1988$;

5 Lindley I, Aschauer H, Seifert JM, Lam C, Brunowsky W, Kownatzki E. Synthesis and expression in $\mathrm{E}$ coli of the gene encoding monocyte-derived neutrophil-activating factor: biological equivalence between natural and recombinan neutrophil-activating factor. Proc Natl Acad Sci USA 1988 85: 9199-203.

6 Van Damme J, Van Beeumen J, Opdenakker G, Billiau A. A novel NH2-terminal sequence-characterised human monokine possessing neutrophil chemotactic, skin-reactive and granulocytosis promoting activity. $\mathcal{F}$ Exp Med 1988; 167: 1364-76.

7 Baggiolini M, Walz A, Kunkel S. Neutrophil-activating peptide 1/interleukin 8, a novel cytokine that activates peptide 1/interleukin 8, a novel cytokine
neutrophils. F Clin Invest 1989; 84: 1045-9.
8 Striter RM, Kunkel SL, Showell HJ, Marks RM. Monokineinduced gene expression of a human endothelial cell-derived neutrophil chemotactic factor. Biochem Biophys Res Commun 1988; 156: 1340-5.

9 Striter RM, Phan SH, Showell HJ, Remick DG, Lynch JP, Genord M, et al. Monokine-induced neutrophil chemotactic factor gene expression in human fibroblasts. $\mathcal{J} \mathrm{Biol}$ Chem 1989; 264: 10621-6.

10 Watson ML, Westwick J, Fincham NJ, Camp RD. Elevation of PMN cytosolic free calcium and locomotion stimulated by novel peptides from IL-1-treated human synovial cell novel peptides from IL-1-treated human synovial cell
cultures. Biochem Biophys Res Commun 1988; 155: 1154-60

11 Garland CF, Lilienfeld AM, Mendeloff AI, Markowitz JA Terrel KB, Garland FC. Incidence rates of ulcerative colitis and Crohn's disease in 15 areas of the United States. Gastroenterology 1981; 81: 1115-24.

12 Binder V. A comparison between clinical state, macroscopic and microscopic appearances of rectal mucosa, and cytologic picture of mucosal exudate in ulcerative colitis. Scand $\mathcal{F}$ Gastroenterol 1970; 5: 627-32.

13 Raab Y, Hällgren R, Knutsson L, Krog M, Gerdin B. A technique for segmental and colonic perfusion in man. $A m \mathcal{F}$ Gastroenterol 1992; 87: 1453-9.

14 Peichl P, Ceska M, Effenberger F, Haberhauer G, Broell H, Lindley IJD. Presence of NAP-1/IL-8 in synovial fluids indicates a possible pathogenic role in rheumatoid arthritis. indicates a possible pathogenic role

15 O'Morain C, Smethurst P, Levi AJ, Peters TJ. Biochemical analysis of enzymatic markers of inflammation in rectal biopsies from patients with ulcerative colitis and Crohn's disease. F Clin Pathol 1983; 36: 1312-6.

16 Colditz I, Zwahlen R, Dewald B, Baggiolini M. In vivo inflammatory activity of neutrophil-activating factor, a nove chemotactic peptide derived from human monocytes. $A m$ Pathol 1989; 134: 755-60.

17 Seitz M, Dewald B, Gerber N, Baggiolini M. Enhanced production of neutrophil-activating peptide-1/interleukin-8 in rheumatoid arthritis. 7 Clin Invest 1991; 87: 463-9.

18 Schroeder JM, Christophers E. Secretion of novel and homologous neutrophil-activating peptides by LPShomologous neutrophil-activating peptides by LPS-
stimulated human endothelial cells. $f$ Immunol 1989; 142: 244-51. 